\title{
Políticas públicas sistêmicas para a redução da violência: a visão de futuro e a resiliência
}

\author{
Alvaro Chrispino* \\ Daniel Evangelho Gonçalves**
}

\section{Resumo}

Um dos grandes problemas contemporâneos envolvendo a educação é a violência escolar. Presença exponencialmente constante na mídia acaba por chocar a sociedade devido à gravidade dos eventos e a quebra da confiança em um espaço antes visto como seguro e sagrado. Esta questão necessita ser tratada como Problema Público urgente. O presente artigo, partindo de episódios de violência escolar recentes, procura demonstrar a importância das medidas de prevenção da violência estruturadas em políticas públicas eficazes materializadas na visão de futuro e na resiliência. Defende a ideia de que o quadro de violência pode ser produzido pela falta de "gratificação de futuro", que permitiria que crianças, jovens e adultos se motivassem a investir hoje, visando o que há de vir. O que ocorre é um sistema de "sorte e azar" onde pessoas com nível social, cultural e financeiro menos abastados, desprezam o futuro e têm seu presente mais dilatado por não anteverem uma meta a ser alcançada ou gratificações por seus esforços, deram, portanto, azar de nascerem num ambiente desfavorecido, e o que lhes acontece de positivo é devido ao acaso. A resiliência é a capacidade de retornar ao estado emocional anterior, após sofrer experiência de estresse, muito comum nos episódios de violência escolar. Com isso, infere-se que para intervir neste quadro de violência, deve a escola (1) ser um espaço de proteção, aprendizagem e socialização, contribuindo para a resiliência do aluno, adaptando-o às mais diversas adversidades presentes em seu meio e (2) criar para essas crianças e jovens geradores de violência, estímulos e condições para se tornarem atores influentes em seu próprio futuro.

Palavras chave: Violência escolar. Políticas públicas. Visão de futuro. Resiliência.

\section{Introdução}

É domingo e a grande mídia estampa como manchete um fato que nos fere a sensibilidade, quer como cidadãos, quer como educadores: "Vale-tudo na

* Doutor em Educação, UFRJ. Professor do Programa de Pós-graduação do CEFET/RJ. E-mail: alvaro.chrispino@gmail.com

** Mestrando do Programa de Pós-graduação em Tecnologia, CEFET/RJ. E-mail: danielgoncalves_ufrj@yahoo.com.br 
Educação"(ARAÚJO, 2013,p.13). A matéria, ilustrada com fotos da Diretora com hematomas, informa que uma Escola Municipal do Rio de Janeiro tem alunos do "morro" e do "asfalto" e que está plantada em uma comunidade dominada pelo trafico. De um lado, uma Diretora, oriunda de família com tradição na área de educação, com 23 anos de exercício no magistério, onde exerceu diversas funções. De outro, um aluno de 15 anos, de uma turma de aceleração da aprendizagem, segundo filho de três, de uma família que vive na comunidade, habitando um cômodo de $12 \mathrm{~m}^{2}$, com renda do Bolsa Família, visto que o pai, pedreiro, está desempregado e tem o hábito de agredir sua mãe.

O espaço de encontro é uma escola pública, que tem a tarefa constitucional de oferecer condições de aprendizagem ao sujeito de Direito: a criança e o jovem.

As versões são divergentes como esperado em episódios deste tipo, além de flutuarem na narrativa quanto mais se afastam do dia em que houve a "explosão", como descreve o jovem aluno. Ao final, ele diz que se excedeu porque "bateu em mulher", mas foi chamado de "diabo" e descontrolou-se. Ela, a Diretora, corretamente, diz que a autoridade deve prevalecer no estabelecimento de limites e a criação de rotinas relacionais socialmente aceitas, e solicita o uso de medidas socioeducativas previstas para o caso. Resume dizendo: "Ele é mau".

No mesmo período de tempo, a grande mídia também noticiou um caso, tão chocante quanto este, agora ocorrido numa Escola Estadual da Grande São Paulo (ALUNOS..., 2013). Desta feita, uma professora foi atingida no rosto por uma lixeira arremessada por estudantes que haviam danificado o quadro de luz a fim de apagar as luzes. Neste caso, fica clara a premeditação: o dano ao patrimônio (quadro de luz), a busca pela situação tida como ideal para o feito (a falta de luz) e o ato violento (arremesso da lixeira).

Os dois casos - para não precisarmos listar inúmeros outros em que professores são atacados por alunos - ferem a nossa sensibilidade, primeiro porque o espaço escolar, antes marcado pela sacralidade, configura-se palco de violência que cresce em número e em requinte de crueldade e, segundo, porque assusta, mais ainda, pela violência de gênero, agora contra uma figura que a memória social de todos nós sempre prezou e reservou em espaço nobre iluminado pela gratidão: a professora.

Após a grande mídia reservar lugar rotineiro para os fenômenos do bullying, fazendo-o mais comum em nossas casas, nos círculos de conversa - sem que 
com isso fossem geradas ações públicas pró-ativas na busca de soluções efetivas - somos atingidos, de novo, na sensibilidade por este tipo de episódio, aqui representado pelos funestos acontecimentos do Rio de Janeiro e de São Paulo.

Ocorre que, de novo, deixamo-nos levar pelos acontecimentos e reagimos com a indignação justa frente a algo que nos configura novo, surpreendente e que nos fragiliza frente ao "inusitado".

Se, desde as primeiras manifestações de violência escolar, onde se deixou o caráter pontual para assumir o caráter de problema sistêmico, tivéssemos - como adultos, mais experientes e mais bem formados - buscado conhecer a gênese possível das ações e modelar alternativas pró-ativas de solução, talvez este exercício nos levasse a conhecer estudos e alternativas metodológicas que contribuiriam para a solução ou diminuição do impacto da violência escolar.

As matérias falam de subnotificação de violências no espaço escolar (ROCHA; ALVES, 2013). Desde 2002 defendemos a necessidade de a escola conhecer o perfil da violência da qual é autora, vítima, palco e laboratório para a aprendizagem (GALVÃO et al., 2010) a fim de permitir o desenho de soluções públicas eficazes (CHRISPINO; CHRISPINO, 2011). Portugal, desde 2006, instituiu o Observatório de Segurança Escolar OSE, que tem como principal tarefa o reconhecimento e tratamento de informações sobre segurança escolar. Escrevendo sobre isso, Sebastião, Alves e Campos (2010, p. 20) informam que o OSE,

Permitiu que, pela primeira vez, exista um conjunto de informação recolhida sistematicamente que possibilita um retrato global da distribuição das situações de violência e indisciplina grave no conjunto do sistema educativo português. Partindo de um ponto de vista teórico aberto aos diversos contributos disciplinares relativos a esta problemática, a informação recolhida possibilita a identificação de um conjunto de elementos críticos e zonas de acumulação de situações de violência, mostrando o seu caráter recorrente, difuso e sensível a estratégias de intervenção prolongadas.

Os dados recolhidos de forma centralizada e sistemática permitiram aos autores informar sobre o fenômeno que observamos: 
Os dados referentes a estas assimetrias de gênero precisam contudo tomar em conta elementos de caraterização do perfil dos protagonistas de situações de violência escolar. Na verdade verifica-se que nos últimos anos letivos a maioria das vítimas do sexo masculino são alunos, enquanto entre as do sexo feminino se constata que os adultos (professores e funcionários) se encontram em número muito elevado. (SEBASTIÃO; ALVES; CAMPOS, 2010, p. 34).

Esse fenômeno vem como fator agravante para desvalorização da carreira do magistério. Apesar de não ser este o foco deste trabalho, lembramos que as matriculas de ingresso nos cursos de licenciatura são declinantes, a carência de professores de ensino médio especialmente é preocupante e só faz aumentar e, agora, aos poucos que se aventuram, chegam os ventos gélidos do risco físico iminente no exercício da profissão (RUIZ; RAMOS; HINGEL, 2007; ROSA; ZAN, 2008).

Parece que o que nos fere sobremaneira a sensibilidade, quer como cidadãos, quer como educadores, é um fenômenos já identificado e quantificado pelos instrumentos de gestão pró-ativa da violência escolar em uso nas terras portuguesas. Esses instrumentos devem atender as funções do "conhecimento, proteção e intervenção" (SEBASTIÃO; ALVES; CAMPOS, 2010, p. 38), buscando "formas de saber mais sistemáticos rigorosos e testáveis que favoreçam a inteligibilidade dos reais contornos dos fenômenos (PINTO, 1996 apud SEBASTIÃO; ALVES; CAMPOS, 2010, p. 39).

Talvez esteja na hora de os formuladores de políticas públicas deixarem os "cantos das cordas", onde se deixaram levar pelos sustos sistemáticos e pela indignação justa causada pelos fatos que se multiplicam, para protagonizarem ações proativas, buscando, no universo escolar, conhecer a realidade, quantificar, categorizar, modelar, propor soluções, avaliar resultados e re-planejar rotinas.

\section{Sobre as Políticas Públicas Sistêmicas}

Além desse item já identificado pelo Observatório da Segurança Escolar (OSE), outros devem constar de um conjunto de Políticas Públicas de Redução da Violência Escolar, alcançando os vários níveis do sistema educacional, como vimos defendendo sistematicamente desde antes: o problema da violência é complexo e solicita visão 
sistêmica, interdisciplinar e multissetorial, sem o que, não passará de esforços pontuais que deixam de utilizar as vantagens inteligentes e necessárias da sinergia.

Dada a complexidade do fenômeno da violência escolar, especialmente pelo caráter de vetor de centralidade das politicas sociais e pela importância comunitária da escola, não é possível imaginar que as ações consequentes estejam exclusivamente tributadas à esfera educacional. A saúde, a promoção e assistência sociais, o sistema de garantias de Direitos da criança e do jovem, a segurança pública, o Judiciário etc., devem ser conclamados a ocupar os espaços de ação que lhes são próprios (CHRISPINO; DUSI, 2008). Essa complexidade sistêmica pode também ser percebida no universo escolar, como bem salientam Galvão et al. (2010) e Ibarrola-Garcia e Iriarte Redín (2012).

Os educadores devem, por sua vez, identificar espaços curriculares e práticas escolares que ofereçam aos estudantes de todos os níveis sentido e significado aos conteúdos e metodologias a que são submetidos por anos a fio (CHRISPINO; SANTOS, 2011).

Considerando que muitos pesquisadores do tema violência escolar atribuem a manifestação violenta do conflito à inexistência do diálogo, ou mesmo às dificuldades do diálogo, é necessário e urgente que se criem espaços de aprendizagem que facultem a comunicação eficaz entre os pares (alunos-aluno, professor-professor) e interníveis (aluno-professor-gestor-comunidade). Isso pode dar-se por meio da disseminação das técnicas de escuta ativa e diálogo na primeira pessoa, por exemplo (LOPES; GOMES, 2012; CHRISPINO; SANTOS; BARROS, 2012; PIGATTO, 2010).

Em primeiro ensaio mais sistemático sobre o tema (CHRISPINO; LAMEGO, 2012), buscamos enumerar a apresentar, mesmo que de forma não exaustiva, alguns aspectos que poderiam compor o rol de políticas públicas que caracterizasse uma ação sistêmica e integrada. Havíamos identificado os seguintes componentes: pesquisas amplas como fonte de diagnóstico; desenvolvimento de competências da comunicação; formação mais adequada em legislação pertinente à função educadora; entendimento sobre o que seja e como se desenvolvem o pertencimento e a territorialidade escolar e a visão/percepção de futuro. Os fatos que iniciam esse trabalho deixam patente e reiteram a necessidade de criação de sistema de pesquisa ampla visando à estruturação de um sistema de acompanhamento e gestão da violência escolar, bem como sugere que devamos observar mais e 
melhor as causas geradoras da violência nos jovens e como intervir proativamente nessas causas. Para tal, propomos retomar a importância da visão de futuro como proposta de identificação de sentido e de significado para o conhecimento e para a escola e, também, a modelagem de abordagem sobre conflito escolar, visando ao melhor entendimento a fim de propor ações eficazes.

\section{Futuro deve trazer gratificação}

Alvin Toffler, o conhecido autor de "O Choque do Futuro", ocupou-se do valor do futuro para a aprendizagem e também da Aprendizagem para o Futuro, título de sua obra publicada no Brasil em 1997 (originalmente nos EUA em 1974, há quase 40 anos). Desta obra, vamos colher as reflexões de Benjamin D. Singer. Este autor defende a ideia da "gratificação de futuro" como aquilo que motiva crianças, jovens e adultos a investirem hoje visando ao futuro. Informa que os alunos que chama de fracos possuem uma visão de futuro de curto prazo. Alunos com algum tipo de sucesso, possuem a capacidade de antever seu futuro em prazo mais dilatado (entre 5 e 10 anos). Do texto de Singer (1977), podemos extrair as seguintes reflexões:

1. Alguns grupos sociais que sofrem restrições financeiras ou sociais, em geral chamados de "imprevidentes", percebem diferentemente o valor do tempo. Estão centrados no aqui e agora. Escreve: "Frente a um futuro duvidoso, o presente dilata-se". Logo, para alguns é extremamente difícil perceber o próprio futuro. (SINGER, 1977, p. 48).

2. A criação da autoimagem projetada no futuro dá sentido ao que fazemos no presente. Ao imaginarem seus papéis-futuros, percebem que os esforços desprendidos no exercício da aprendizagem podem ser justificados. Ele "vai além de suas próprias limitações e entra nas possibilidades do futuro". (SINGER, 1977, p. 50).

3. Informa sobre pesquisa em que jovens "não delinquentes tinham uma perspectiva de tempo mais dilatada que os delinquentes" e, lembrando Kurt Lewin, escreve que "uma pessoa provavelmente se voltará para o futuro se sentir que lhe é acessível alguma meta a que dê elevado valor, enquanto a crença de que esta meta está além do seu alcance, restringi-la-á a orientar-se para o presente" (SINGER, 1977, p. 55).

4. Crianças oriundas de grupos sociais vulneráveis tendem a tributar a forças externas o fato de elas receberem algum tipo de 
recompensa futura. Isso não acontece com crianças de grupos sociais bem aparelhados e, muito menos, com qualquer criança do pré-escolar. "Ficou claro que durante o período de escola elementar algo acontece para fazer com que crianças de certos grupos sociais desprezem o futuro" (SINGER, 1977, p. 56).

Façamos uma viagem no tempo e convidemos Howard Zehr (2008) para apresentar suas reflexões sobre a capacidade de crianças e jovens pensarem e decidirem sobre o próprio futuro. Podemos assim sintetizar suas ideias:

1. [...] a linha divisória entre as classes baixa e média alta da nossa sociedade está no sentido de escolha e de poder. Essas últimas acreditam que são senhoras do próprio destino... têm escolhas e algum poder real de determinar o seu futuro. (ZEHR, 2008).

2. Muito pobres não acreditam que são capazes de determinar o próprio futuro. $\mathrm{O}$ que lhes acontece deve-se ao acaso. Se o sucesso lhes sorri, deve-se mais à sorte do que ao esforço e às oportunidades construídas: "Se são presos por um delito, isto se deve mais ao azar do que a algo que tenham feito. Tenham ou não o poder de fazer escolhas reais, muitos não acreditam que podem, e isto é o mais significativo" (ZEHR, 2008, p. 53).

3. Estes jovens não veem relação entre suas escolhas e o futuro. Cita entrevistas de Parkers Rossman com jovens em conflito com a lei:

Todos os dias esses jovens veem pessoas inocentes sendo presas. Todos os dias veem pessoas culpadas em liberdade. Para eles praticamente não há relação entre delito e punição. Ao contrário, na sua perspectiva a punição é mais ou menos como a chuva que às vezes cai, às vezes não cai: ela molha igualmente os justos e os injustos. A maioria dos jovens tem a expectativa de passar pela experiência de ser pego e punido em algum momento da vida. Como tudo no futuro que enxergam, isto é algo que simplesmente acontece, e que está sob o controle de forças totalmente irresistíveis. (ZEHR, 2008, p. 53)

A essa descrição de Zehr, podemos chamar de sistema sorte-azar que, na visão destes jovens, é responsável pelo presente que vivem e pelo futuro que os espera. 
Se esta análise é surpreendente para alguns, será mais ainda quando informarmos que estes mesmos pressupostos já estavam no trabalho de Singer(1977), de que nos utilizamos antes:

O antropólogo Walter B; Miller ilustra isso [imagem de futuro difusa] bem com seu quadro clínico dos jovens de classes pobres que se reúnem em bandos: "muitos indivíduos das classes inferiores sentem suas vidas subordinadas a um conjunto de forças sobre as quais têm relativamente pouco controle. Essas forças não se equacionam diretamente com as forças sobrenaturais da religião formalmente organizadas, relacionando-se mais com um conceito de destino, ou do homem como peão de forças mágicas. Não raramente, esta visão muitas vezes implícita do mundo é associada à concepção da futilidade última do esforço dirigido para um alvo" (p. 50).

A ideia antiga defendida por Singer - retomada em certa maneira por Zehr -, é também defendida por Eduardo Giannetti (2005) quando estrutura sua obra "O Valor do amanhã", identificando como pontos centrais o presente e o futuro. Escreve ele que crianças submetidas a testes específicos, respondem de forma diferente à pergunta: até que ponto uma criança é capaz de esperar?

Informa que o experimento clássico consiste na oferta à criança do seguinte dilema: a criança está numa sala e, ao alcance de sua mão, está disponível um pequeno sino que ela pode tocar a qualquer momento. Se o fizer, imediatamente, um adulto adentra a sala e lhe entregará uma unidade de um doce. Se ela aguardar até que um adulto apareça por si mesmo, receberá duas unidades do doce. A criança permanece na sala onde pode ver, e não tocar, as duas opções expressas em um doce e dois doces. $\mathrm{O}$ tempo máximo previsto para a entrada do adulto é de 20 minutos.

O resultado imediato do teste informa que crianças até 4 anos invariavelmente tocam o sino, com alguma variação de tempo. Para as que possuem 12 anos, $60 \%$ delas aguardam o tempo máximo. Infere-se que é entre quatro e 12 anos que se desenvolvem as funções mentais superiores responsáveis pelas escolhas intertemporais, sendo ai o período propício para a aprendizagem da relação presente-futuro (GIANNETTI, 2005, p. 89-90).

A melhor contribuição deste estudo surge com o acompanhamento das crianças que participaram dos chamados "testes de gratificação postergada", demonstrando uma relação da escolha com os resultados de longo prazo de suas vidas: 
As crianças que, já a partir dos quatro anos, revelaram maior disposição e aptidão à espera obtiveram notas mais altas no ensino médio, maior taxa de acesso à universidade e melhor desempenho acadêmico. Na idade adulta, elas apresentaram outros traços pessoais e sociais correlatos, como menor incidência de tabagismo e abuso de drogas, menor índice de delinquência e de conflitos familiares sérios. (GIANNETTI, 2005, p. 91).

Logo, os fatores de dificuldades sociais apresentados nas reportagens envolvendo os promotores dos episódios da violência, e que estão ligados às dificuldades gerais e comuns, podem sofrer intervenções positivas se consideradas a capacidade de criar imagem de futuro pessoal (Toffler e Singler), a capacidade de perceber-se capaz de influir no próprio futuro (Hezr) e a aprendizagem sobre o valor de esperar para colher mais e melhor no futuro (Giannetti). Em síntese, essas crianças e jovens que são promotores de violência merecem receber estímulos e condições de se perceberem sujeitos capazes de influenciar na formação do próprio futuro, colhendo os frutos que essa autoimagem traz para eles próprios.

\section{A capacidade de recuperar-se de pressões externas: resiliência}

A escola é, em geral, referenciada como um lugar de proteção de e para crianças e jovens. Dependendo de como esta escola é gerida, de sua capacidade de dar sentido e significado aos conhecimentos e ao tempo que os estudantes permanecem nela, isso pode dar-se com maior ou menor intensidade.

As narrativas sobre episódios violentos em ambientes escolares, em geral, envolvem crianças e jovens sem capacidade de percepção de seu futuro, bem como lista uma série de limitações físicas, emocionais, financeiras etc. a que estão submetidas. O caso que inicia este trabalho detalha com riqueza de pormenores as restrições financeiras do jovem agressor e as constrições emocionais a que está submetido, pela família emocionalmente desassistida. É fato que o jovem está sob forte pressão, assim como também é fato que nem todos os emocionalmente desassistidos e que sofrem pressão são violentos, tais quais o jovem que protagonizou a infeliz história.

Neste ponto, gostaríamos de trazer à discussão o conceito de resiliência: 
O conceito de resiliência, utilizado inicialmente pela Física e pela Engenharia, designa a capacidade de um material ou objeto sofrer algum tipo de pressão pelo meio, sendo que, logo após essa ação, retomaria sua forma e sua condição de normalidade, sem sofrer alterações (FERREIRA, 1975 apud PESSOA; LIBÓRIO, 2011, p. 167).

Os autores esclarecem que a apropriação pelas ciências humanas, especialmente Educação e Psicologia, do conceito de resiliência não ocorreu de forma simples ou mesmo direta, considerando a complexidade do ser humano, com atenção especial ao fato de que, nas ciências exatas, resiliência é pontual e unidirecional e, nos seres humanos, processual e contextualizada. Não é tranquila a definição de resiliência no universo social, mas pode-se considerar como consenso que seja: "O processo de desenvolvimento 'bem-sucedido' de uma pessoa, mesmo frente a adversidades" ou mesmo riscos, realçando de imediato a dificuldade de se padronizar o que seja risco para cada indivíduo. Aceita-se, pois, a definição advinda da ideia de que há riscos universais às populações infanto-juvenis, tais como: trabalho infantil, divórcio dos pais, residência em regiões com alto índice de exclusão, vulnerabilidade, social etc...

Libório, Coêlho e Castro (2011) desenvolveram pesquisa a partir dos dados da Pesquisa Nacional sobre Juventude Brasileira (KOLLER et. al., 2005) e entrevistaram 7.482 adolescentes, buscando entender os fatores de risco e de proteção presentes na vida desses adolescentes. A nosso ver, além da contribuição dos resultados e análises da pesquisa, os autores trazem importante contribuição por conta da revisão teórica que fundamenta o trabalho.

Os autores informam que no artigo utilizaram o conceito de resiliência construído em pesquisa realizada em catorze países, representantes de cinco continentes, pelos participantes do Internacional Resilience Project (IRP), que examinaram padrões e processos protetivos na vida dos 1.500 adolescentes respondentes. Os riscos abrangiam pobreza, guerra, deslocamento social, degradação cultural, genocídios, violência, marginalização, abuso de álcool e drogas, quebra de vínculos familiares, doenças mentais nas crianças ou nos pais e gravidez precoce.

Após esta delimitação dos riscos, os pesquisadores de cada país deveriam considerar os adolescentes que, apesar de expostos a pelo menos três dos riscos listados, foram identificados como quem se desenvolveu bem, "apesar dos riscos enfrentados" (p. 112). A obtenção de dados qualitativos 
deu-se por meio de entrevistas semiestruturadas efetuadas com 89 jovens (entre 12 e 23 anos). O conceito de resiliência construído não acolhia uma explicação universal, ou uniforme, por estas não darem conta da "amplitude e complexidade do fenômeno" (p. 113). Percebeu-se que os adolescentes "saudáveis" apresentavam um conjunto de procedimentos que os permita "navegar" por sete temas ou tensões que foram resolvidas ou superadas pelos jovens, de alguma forma: "acesso a recursos materiais, identidade, relacionamentos, coesão social, aderência cultural, poder e controle e justiça social" (p. 113).

Os resultados - amplos - podem ser sintetizados para o escopo deste trabalho como: O nível de insatisfação é baixo para ambos os sexos. Para a maioria dos respondentes ela é boa $(34,3 \%)$, razoável $(38,9 \%)$. Outros valores foram: muito ruim $(5,7 \%)$, ruim $(7,1 \%)$ e muito boa $(14,0 \%)$.

No que refere à confiança e à relação de vínculo dos adolescentes, temos que:

\section{Quadro 1}

\begin{tabular}{|l|l|l|}
\hline \multicolumn{1}{|c|}{ Tema pesquisado } & Meninos (\%) & Meninas (\%) \\
\hline Confiam na maioria dos professores & 44,1 & 41,9 \\
\hline Dizem poder contar com os professores e equipe escolar & 44,9 & 45,4 \\
\hline Confiam nos amigos da escola & 45,1 & 46,8 \\
\hline Gostam da maioria dos amigos da escola & 72,0 & 73,8 \\
\hline Gostam da maioria dos professores & 54,5 & 61,3 \\
\hline Gostam de ir a escola & 59,0 & 68,2 \\
\hline Acham que os estudo tem importância para o futuro & 94,2 & 96,8 \\
\hline Recebem incentivos das famílias para os estudos & 87,0 & 89,2 \\
\hline Se acham bons estudantes & 54,6 & 59,5 \\
\hline Têm desejo de entrar no ensino superior & 73,1 & 83,6 \\
\hline Acham que tem condições de entrar no ensino superior & 53,5 & 51,4 \\
\hline
\end{tabular}

Fonte: os autores (2013).

Os autores, ao analisarem os resultados, chamaram a atenção para alguns aspectos:

- os respondentes expressaram baixos índices de insatisfação com a escola, bem como um número significativo de adolescentes informou gostar da maioria dos professores;

- os respondentes parecem reconhecer que o estudo é importante para o futuro e que terão dificuldade para ingressar na educação superior; 
- um problema é a baixa autoestima expressa quando os respondentes se classificam como bom estudante,

- realçam que, para $1 / 3$ dos respondentes, a escola não contribui para a resolução bem-sucedida de algumas das sete tensões usadas como parâmetro de estudo. Lembram que a formação de vínculos de confiança é indispensável para a sensação de bem-estar, necessários para a resiliência e para a formação do autoconceito e da autoestima.

Realçando o papel dos professores na construção dos vínculos de confiança e das relações no interior da escola, os autores informam ser a escola um lugar possível para que tais aspectos formativos ocorram, e concluem escrevendo que,

Os resultados, combinados com as teorias mencionadas, convidam para refletir sobre a necessidade de a escola se configurar como espaço de aprendizagem, de trocas afetivas, de socialização, de construção de autonomia e de ação protagônica. Ao desenvolverem tais possibilidades nos seus alunos e alunas, as escolas estariam ampliando as dimensões de sua influência sobre os estudantes, sendo capazes de se configurar como espaços de proteção e geradores de processos de resiliência. (LIBÓRIO; COÊLHO; CASTRO, 2011, p. 133).

\section{Quase mais do mesmo como conclusão}

Iniciamos narrando fatos infelizes que novamente marcam a escola brasileira. Recorrentemente, com períodos menores entre si e intensidades mais agudas, os episódios violentos nos chegam.

Por mais que concordemos que o número de pesquisas acadêmicas em torno do grande tema violência escolar e suas possíveis derivações aumentam, temos dificuldade de identificar ações que se caracterizam como políticas públicas institucionalizadas para sistemas educacionais. Têm-se pesquisas e ações pontuais que carecem de oportunidade para crescer a fim de produzir conhecimentos generalizáveis ou que possam ser replicadas em sistemas.

A cada dia fica mais premente a necessidade de que a violência escolar se transforme efetivamente em Problema Público e, após isto, se desdobrem 
as etapas conhecidas em qualquer um dos modelos das politicas públicas eficazes e transparentes. As experiências acadêmicas ou escolares empíricas precisam ser tecidas como rede para que cada experiência contribua na busca de solução adequada.

A cada dia, entre lágrimas e gemidos, hematomas e ameaças, por meio da midiatização, os acontecimentos violentos pontuais são transformados em regra geral, formando senso comum equivocado, que mais assusta, mais atormenta, mais fragmenta, mais desespera. Porque os índices crescem e não se vê nenhuma ação governamental eficaz - ao tempo que é um tema de prioridade na mídia "domina a impressão de uma epidemia de raiva brutal, de um perigo crescente nos estabelecimentos escolares" (DEBARDIEUX, 2006, p. 15), que precisa ser revertido, sob risco de colapso de muito mais difícil retorno.

Como sinal de esperança e de possibilidade de reversão do quadro pessimista que se dissemina, lembremos, novamente, a necessidade de se dar sentido e significado à escola, buscando fazê-la retornar a centralidade social, posição essa que os episódios violentos teimam em desestabilizar.

É possível tal intento e, como reforço desta afirmativa, buscamos como exemplo Victor Frankl que já propalava a importância do sentido, do significado e da posição positiva frente à vida, no que ficou conhecido como Logoterapia.

Médico em Viena (1930), foi aluno de Freud e de Adler, deixando-se influenciar pela filosofia existencialista de Heidegger, Scheler e Jaspers (REDORTA; OBIOLS; BISQUEIRA, 2006). Durante os anos trevosos do nazismo (1942-1945), foi recolhido aos campos de concentração de Auschwitz e Dachau, junto com sua família. Ali morreram seu pai, sua mãe, seu irmão e sua mulher. Neste extremo de dor, Frankl pergunta-se como achar alternativas para superar as dores que vivia. Elegeu para si três princípios: sobreviver, ajudar e aprender. Teve oportunidade de auxiliar a muitos utilizando os sonhos de cada qual e concitando-os a superar as angústias e dores do presente por conta da "gratificação do futuro".

A pergunta que surge pode ser o que pode fazer com que alunos com este comportamento se motivem e deixem os comportamentos violentos? Victor Frankl obteve a resposta enquanto observava as atrocidades dos campos de concentração: 
projetá-los para o futuro, descobrindo o que pode motivá-los a buscar sair da estática e imprimirem um ritmo de crescimento pessoal e de melhoria da autoestima.

Ocorre que este movimento não é natural porque ele solicita "gasto de energia do sistema". Essa energia extra para iniciar e dirigir o processo só pode vir dos adultos, experientes e mais preparados: professores, gestores educacionais de todos os níveis e pais preocupados e parceiros.

Que venham as ações proativas a fim de que a ideia falsa de que não há mais solução não tome (mais) corpo e que não pensem que os alunos violentos são "felizes" protagonizando dores e angústias a professores e a outros alunos.

Como iniciamos com exemplos de violências escolares, permitimo-nos encerrar também com um, cujo desfecho sintetiza a proposta apresentada aqui. A matéria tem como titulo "Professor é baleado por aluno dentro de sala de aula em Sergipe" (VAZ, 2013). Informa que dois alunos, um de 15 e outro de 16 anos discutiram em sala de aula e um sacou de uma arma e fez um disparo que, acidentalmente, atingiu um professor que fazia a chamada dos alunos.

Tomadas as providencias para atendimento do professor, que sobreviveu, a diretora informa que os dois adolescentes não possuem histórico de violência no colégio e arremata: "Eles são alunos da casa e nós daremos todo apoio social e psicológico que eles necessitarem, inclusive para as famílias, que estão muito abaladas, e para os demais alunos da escola"

Eis tudo, “eles são alunos da casa e nós daremos todo apoio"...

\section{Referências}

ARAÚJO, V. Vale tudo na educação. O Globo, Rio de Janeiro, p. 13, mar. 2013.

ALUNOS jogam lixeira em professora na Grande SP. Portal G1. São Paulo, mar. 2013. Disponível em: <http://g1.globo.com/sao-paulo/noticia/2013/03/alunosjogam-lixeira-em-professora-na-grande-sp.html>. Acesso em: 01 maio 2013.

CHRISPINO, A.; CHRISPINO, R. S. P. A judicialização das relações escolares e a responsabilidade civil dos educadores. Ensaio: aval. pol. públ. educ., Rio de Janeiro, v. 16, n. 58, p. 9-30, jan./mar. 2008. 
CHRISPINO, A.; DUSI, M. L. H. M. Uma proposta de modelagem de política pública para a redução da violência escolar e promoção da Cultura da Paz. Ensaio: aval. pol. públ. Educ., Rio de Janeiro, v. 16, n. 61, dez. 2008 . Disponível em: $<\mathrm{http}: / / \mathrm{www}$. scielo.br/scielo.php?script=sci_arttext\&pid=S010440362008000400007\&lng=pt\&nrm=iso >. Acesso em: 05 abr. 2013.

CHRISPINO, A.; LAMEGO, M. Visão e políticas integradas no atendimento à violência escolar ou por que os males de Pandora não se resolvem com D.Quixote. In: GOMES, C. A.; FERREIRA, G. A.; KOEHLER, S. M. F. (Org.). Culturas de violência, culturas de paz: da reflexão à ação de educadores, operadores do Direito e defensores dos direitos humanos. 1 ed.Curitiba (PR): Editora CRV, 2012.

CHRISPINO, A.; SANTOS, T. C. dos. Política de ensino para a prevenção da violência: técnicas de ensino que podem contribuir para a diminuição da violência escolar. Ensaio: aval. pol. públ. Educ., Rio de Janeiro, v. 19, n. 70, mar. 2011. Disponível em <http://www.scielo.br/scielo.php?script=sci_ arttext\&pid=S0104-40362011000100005\&lng=pt\&nrm=iso $>$. Acesso em: 01 mai. 2013.

CHRISPINO, A.; SANTOS, D. P. ; BARROS, G. N. P. Aprender a comunicar-se: Primeiro passo para melhor convivência escolar. In: MONTEIRO, V. B.; SILVA, K. R. S da. (Org.). Mediação de conflitos: direitos humanos e acesso à justiça. 1ed. Recife (PE): Gajop. 2012.

DEBARDIEUX, É. Violência na escola: um desafio mundial? Lisboa: Instituto Piaget, 2006.

GALVÃO, A. et al . Violências escolares: implicações para a gestão e o currículo. Ensaio: aval. pol. públ. Educ., Rio de Janeiro, v. 18, n. 68, set. 2010 . Disponível em: $<\mathrm{http} / /$ www.scielo.br/scielo.php?script=sci_arttext\&pid=S010440362010000300002\&lng=pt\&nrm=iso $>$. Acesso em: 01 mai. 2013.

GIANNETTI, E. O valor do amanhã. São Paulo: Companhia das Letras, 2005.

IBARROLA-GARCIA, S.; IRIARTE REDIN,C. La Convivencia escolar em positivo: Mediacion y resolucion de conflitos. Madrid: Ediciones Pirámide, 2012. 
KOLLER, S. H et al. Juventude brasileira: comportamentos de risco, fatores de risco e de proteção.Washington, DC: World Bank, 2005. Relatório Técnico.

VAZ, A. Professor é baleado por aluno dentro de sala de aula em Sergipe. Jornal da Ciência eletrônico, [S. 1.], JC-email 4696, 02 abr. 2013. Disponível em: $<$ http:// www.jornaldaciencia.org.br/Detalhe.jsp?id=86440>. Acesso em: 03 abr. 2013.

LIBÓRIO, R .M. C.; COÊLHO, A. E. L.; CASTRO, B. M. Escola: risco ou proteção para adolescentes e jovens? In: DELL'AGLIO, D. D.; KOLLER, S. H. (Org.). Adolescência e Juventude: vulnerabilidade e contexto de proteção. São Paulo: Casa do Psicólogo, 2011.

LOPES, R. B.; GOMES, C. Paz na sala de aula é uma condição para o sucesso escolar: que revela a literatura? Ensaio: aval. pol. públ. Educ. [online], Rio de Janeiro, v. 20, n.75, p. 261-282, abr./jun. 2012. ISSN 0104-4036. Disponível em: <http://dx.doi. org/10.1590/S0104-40362012000200003 $\geq$. Acesso em: 01 mai. 2013.

PESSOA, A. S. G.; LIBÓRIO, R. M. C. Nível de confiança de adolescentes e jovens em instituições e processos de resiliência. In: DELL'AGLIO, D. D.; KOLLER, S. H. (Org.). Adolescência e Juventude: vulnerabilidade e contexto de proteção. São Paulo: Casa do Psicólogo, 2011.

PIGATTO, N. A docência e a violência estudantil no contexto atual. Ensaio: aval. pol. públ. Educ. [online], Rio de Janeiro 2010, v. 18, n. 67, p. 303-324, abr./jun. 2010. Disponível em: <http://dx.doi.org/10.1590/S0104-40362010000200007>. Acesso em: 01 maio 2013.

REDORTA, J.; OBIOLS, M.; BISQUEIRA, R. Emocion y conflito: a renda a manejar las emociones. Barcelona: Paidós, 2006.

ROCHA, C.; ALVES, M. Rotina de violência não vira estatística. O Globo, Rio de Janeiro, p. 14, 31. mar. 2013.

ROSA, M .I. P. ; ZAN, D.P. (Coord.). Faculdade de Educação: Comissão de Licenciaturas. Jornal da educação: CEDES, Campinas, mar., 2008, Disponível em: $<$ http://www.cedes.unicamp.br/jornal_educacao_6/JE_06_documento_ licenciatura.htm $\geq$. Acesso em: 01 maio de 2013. 
RUIZ, A. I; RAMOS, M. N.; HINGEL, M. Escassez de professores no Ensino Médio: propostas estruturais e emergenciais. Brasília, DF: MEC; CNE; CEB, 2007. Relatório produzido pela Comissão Especial instituída para estudar medidas que visem a superar o déficit docente no Ensino Médio (CNE/CEB). Disponível em: <http://portal.mec.gov.br/cne/arquivos/pdf/escassez1.pdf>. Acesso em: 01 maio 2013.

SEBASTIÃO, J.; ALVES, M. G.; CAMPOS, J. Violência na escola e sociedade de risco: uma aproximação ao caso português. In: SEBASTIÃO, J. (Org.). Violência na escola: tendências, contextos, olhares. Chamusca (Portugal): Edições Cosmos, 2010.

SINGER, B. D. A imagem-papel focalizada no futuro. In: TOFFLER, A. Aprendendo para o futuro. [S. 1.]: Editora Artenova, 1977.

ZEHR, H. Trocando as lentes: um novo foco sobre o crime e a justiça. São Paulo: Palas Athenas, 2008.

Recebido em: 22/05/2013

Aceito para publicação em: 25/07/2013

\section{Systemic Public Policies for the Violence Reduction: The vision of future and the resilience Abstract}

One of the great contemporary problems involving education is the school violence. The exponentially constant presence on the media ends up shocking society due to the gravity of the events and the breach of trust in the locale previously considered as safe and sacred, more and more this issue needs to be addressed as a Public Problem. This present work, setting out from recent school violence episodes, seeks to demonstrate the relevance of the violence prevention measures structured in effective public policies materialized in the vision of future and in the resilience. It defends the idea that the violence situation can be created by the lack of "future gratification", which would allow children, young adults and adults to motivate to invest today aiming at what is yet to come. What happens is a system of "luck and misfortune" where people with poorer social, cultural and financial levels despise the future and experience the present in an enlarged way due to not foreseeing an objective to be achieved or gratifications for their efforts. Therefore, they had the 
misfortune of being born in a less privileged environment, and everything positive that occurs to them is by chance. The resilience is the capacity of returning to the previous emotional state after suffering stressful experiences, which is very common in school violence episodes. Therewith, it is inferred that to intervene in this violence situation, the school must (1) become a place of protection, learning and socialization, contributing for the resilience of the students, adapting them to many diverse adversities present in their environment and (2) create incentives and conditions for those children and young adults who generate violence so they can become influential actors in their own futures. Keywords: School violence. Public policies. Vision of future. Resilience.

\section{Políticas Públicas Sistémicas en pro de la Reducción de la Violencia: visión de futuro y resiliencia Resumen}

Uno de los grandes problemas contemporáneos que también afecta a la educación es la violencia escolar. Presencia exponencialmente constante en los medios acaba chocando a la sociedad debido a la gravedad de los hechos y a la quiebra de confianza en un espacio antes visto como seguro y sagrado. Es necesario tratar este asunto como Problema Público urgente. Este artículo parte de episodios de violencia escolar recientes y busca demostrar la importancia de las medidas de prevención de la violencia estructuradas en políticas públicas eficaces, materializadas en la visión de futuro y en la resiliencia. Defiende la idea de que el cuadro de violencia puede originarse debido a la falta de "gratificación de futuro", que permitiría que niños, jóvenes y adultos se motivaran y quisieran invertir hoy, con miras al futuro. Lo que ocurre es un sistema de "suerte y mala suerte" donde personas con nivel social cultural y financiero menos próspero, desprecian el futuro y tienen su presente más dilatado por no imaginar una meta a ser alcanzada o gratificaciones por sus esfuerzos, tuvieron la mala suerte, por lo tanto, de nacer en un ambiente desfavorecido, y lo que les pasa de positivo se debe al acaso. La resiliencia es la capacidad de retornar al estado emocional anterior, después de sufrir experiencia de estrés, muy común en los episodios de violencia escolar. De lo que se infiere que para intervenir en este cuadro de violencia, la escuela debe ser (1) un espacio de protección, aprendizaje y socialización, contribuyendo de ese modo para la resiliencia del alumno, adaptándolo a las más diversas adversidades presentes en su medio y (2) crear para los niños yjóvenes generadores de violencia, estímulos y condiciones para que puedan convertirse en actores influyentes de su propio futuro.

Palabras clave: Violencia escolar. Politicas públicas. Visión de futuro. Resiliencia. 